\title{
Tendency of Loop Formation of Oligosilsesquioxanes Obtained from (4-Substituted phenyl)trimethoxysilane Catalyzed by Benzyltrimethylammonium Hydroxide in Benzene
}

\author{
Chitsakon PAKJAMSAI and Yusuke KAWAKAMI ${ }^{\dagger}$ \\ School of Materials Science, Japan Advanced Institute of Science and Technology (JAIST), \\ Asahidai 1-1, Tatsunokuchi, Ishikawa 923-1292, Japan
}

(Received October 14, 2003; Accepted March 15, 2004; Published June 15, 2004)

\begin{abstract}
Products in hydrolysis of (4-substituted phenyl)trimethoxysilane in the presence of benzyltrimethylammonium hydroxide in benzene was studied by matrix-assisted laser desorption/ionization-time of flight mass spectroscopy. In the benzene soluble fraction of $4 \mathrm{~h}$ reaction, oligosilsesquioxanes containing 6 to 9 silicon atoms with or without loops were observed. (4-Dimethylaminophenyl)trimethoxysilane gave the fraction containing 6 silicon atoms the least (3\%), and 9 silicon fraction the most (36\%). Oligosilsesquioxanes containing 9 silicon atoms were formed the least among the products for [4-methoxy- (10\%), 4-methyl- (22\%), non- (3\%), and 4-phenyl- (13\%) substituted phenyl]trimethoxysilanes. Oligosilsesquioxanes containing 6 to 8 silicon atoms were the major components of the product irrespective of the substituent. Maximum degree of condensation $(f)$ was 0.8 for $\mathrm{S}_{8}$, and fully condensed structure was not found. The maximum $f=1.00$, and completely closed loop was found in $\mathrm{S}_{9}$ with one $\mathrm{OH}$ group remaining.

[DOI 10.1295/polymj.36.455]

KEY WORDS Phenyltrimethoxysilane / Hydrolysis / Intra and Intermolecular Condensation / Substituent Effect / MALDI-TOF Mass Spectroscopy / Degree of Condensation / Silsesquioxane with Loop /
\end{abstract}

Much interest is paid to polysilsesquioxane by many researchers in academia and industry as a new competitor to polysiloxane. This raw material has excellent thermal, mechanical, chemical and weathering properties. ${ }^{1,2}$ Hydrolysis of trichlorosilane $\left(\mathrm{RSiCl}_{3}\right)$ or trialkoxysilane $\left(\mathrm{RSi}\left(\mathrm{OR}^{\prime}\right)_{3}\right)$ gives polysilsesquioxane with the formal structure $\left[\mathrm{RSiO}_{1.5}\right]_{n}$, but the actual product is a complex mixture of various types, such as insoluble gel, crystalline compounds, or oil. ${ }^{3}$ The product distribution depends on reaction conditions, such as solvent, concentration, catalyst, temperature, and the substituent $\mathrm{R}$ group in the starting material. ${ }^{1,3-7}$ Most of the interests have been focused on hydrido, vinyl and epoxy functional polysilsesquioxane, and the products have been used in high porous materials, ${ }^{8}$ nano-composite materials, ${ }^{9}$ and catalyst for polymerization, ${ }^{10}$ although many unidentified products still exist in the system.

During the reaction, both "intermolecular" to give randomly branched polymers and ladder polymers, ${ }^{11}$ and "intramolecular" to give loop structure which eventually forms cyclic polyhedral cage products occur $^{4,5,12,13}$ (Figure 1).

The products usually contain unreacted silanol groups depending on their structures. These unreacted silanols have a great influence on the reactivity, viscosity and solubility of the polymer in subsequent processing step. For qualitative/quantitative analysis of remaining silanols in the product, infrared spectroscopy technique (IR) has been widely used. However, determination of silanols by IR is limited by many factors, such as baseline correction, the necessity of internal standard.

Recently, Wallace et al. ${ }^{14}$ reported that high resolution matrix-assisted laser desorption/ionization-time of flight mass spectrometry (MALDI-TOF MS) could be applied to identify the products with loop structure formed by intramolecular condensation of silanols from $n$-propyl-, $n$-decyl-, and 3-methacryloxypropyltrimethoxysilane. It was pointed out that there was a significant substituent effect on intramolecular condensation.

Meanwhile, intense focus have been given to the cage shape polysilsesquioxane, especially to octa-functional cubic octasilsesquioxane, octa functional pentacyclo[9.5.1.1 $1^{3,9} \cdot 1^{5,15} \cdot 1^{7,13}$ ]octasiloxane, or $\mathrm{T}_{8}$ derivatives, such as hydrido-functionalized $\mathrm{T}_{8}-\mathrm{H}$, or dimethylsilyloxy-functionalized $\mathrm{T}_{8}-\mathrm{OMe}_{2} \mathrm{SiH}$ as a component to construct nano-structured composite systems. ${ }^{15}$ Such $\mathrm{T}_{8}$ systems act not simply as constituent of nanohybrid systems, but can function in advanced display technology as a support for amorphous and functional dye dispersant system, when the radial direction of attachment of functional groups is considered. To realize such systems, it is essential to establish a method to obtain aromatic substituted cubic $\mathrm{T}_{8}$ systems.

${ }^{\dagger}$ To whom correspondence should be addressed (Tel: +81-761-51-1630, E-mail: kawakami@jaist.ac.jp). 

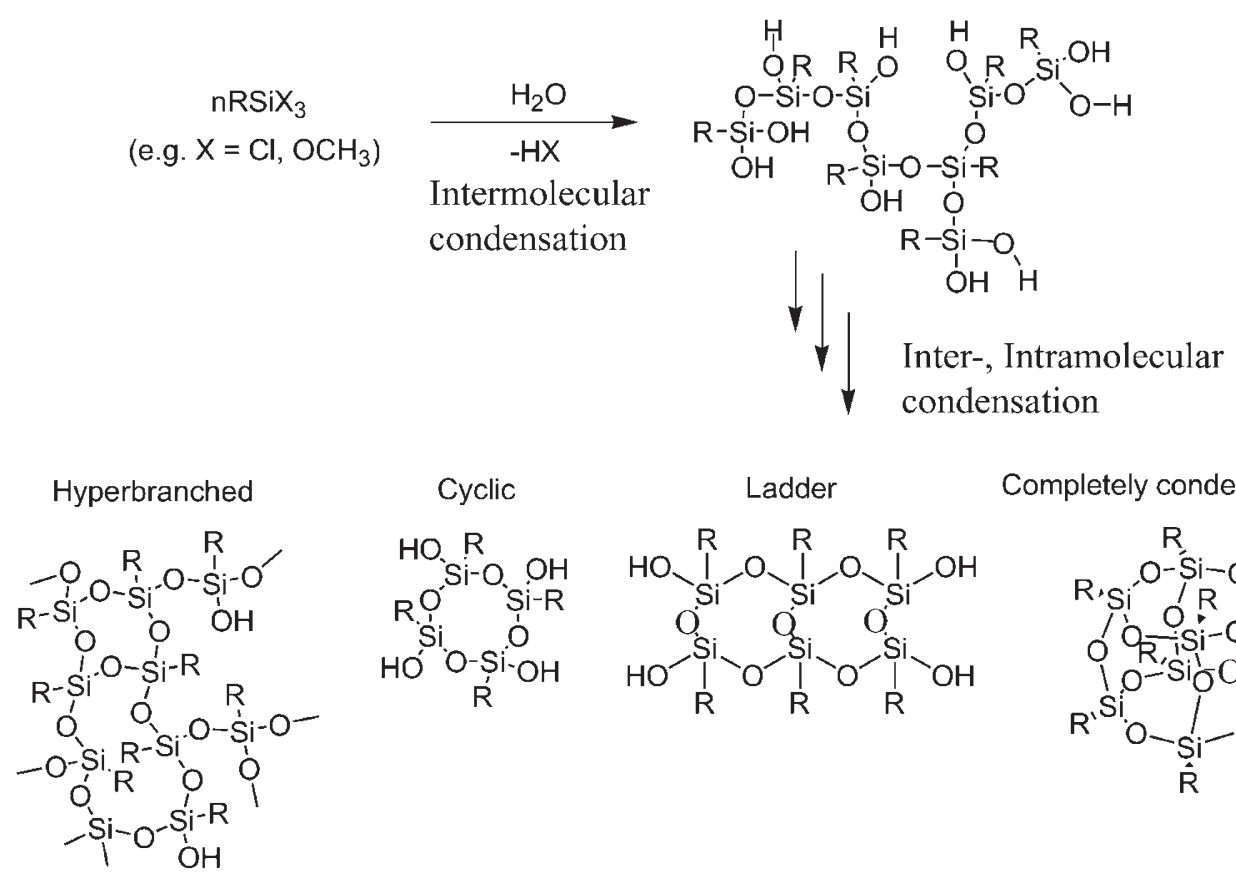

Completely condensed cage

Figure 1. Possible reaction products in hydrolysis of $\mathrm{RSiX}_{3}$.

The objective of this study is to analyze the benzene soluble components in hydrolysis and condensation reactions of (4-substituted phenyl)trimethoxysilane, which has not been much studied compared with functionalized alkyl-substituted trichlorosilane, ${ }^{4,14}$ to obtain basic information by MALDI-TOF MS about the influence of structure of aromatic ring on loop formation in such system.

\section{EXPERIMENTAL}

\section{General}

Fourier transform-infrared (FT-IR) spectra of the oligosilsesquioxanes were obtained as $\mathrm{KBr}$ disc on a JASCO VALOR-III (resolution of $4 \mathrm{~cm}^{-1}, 400$ $4000 \mathrm{~cm}^{-1}$ ) with TGS detector at room temperature. ${ }^{1} \mathrm{HNMR}$ spectra $(300 \mathrm{MHz})$ were obtained on a Varian Gemini 2000 in $\mathrm{CDCl}_{3}$. Solid state ${ }^{29} \mathrm{Si} \mathrm{NMR}$ spectra $(79.46 \mathrm{MHz})$ were obtained on a Varian NMR INOVA 400. For MALDI-TOF MS (Shimadzu-Kratos Kompact MALDI III) analysis, the matrix 2,5-dihydroxybenzoic acid 98\% (DHBA) was dissolved in THF $(50 \mathrm{mg} / \mathrm{mL})$, and mixed with the sample solution $(0.1 \mathrm{mg} / \mathrm{mL}$ in THF) in $1: 1 \mathrm{v} / \mathrm{v}$ ratio. The samples were dried in air at least for $30 \mathrm{~min}$, and the measurement was done in linear mode, with UV laser $(337 \mathrm{~nm})$. The spectra were calibrated by the use of bradykinin, and insulin B chain, oxidized. All of the data was collected by laser power more than $100 \mathrm{~W}$, above the threshold in positive ion mode with accumulation of 50-200 shots. Size exclusion chromatography (SEC) was performed on a JASCO high speed liquid chromatograph, model Gulliver 900 with the combination of Shodex KF-801 (exclusion limit: polystyrene, $1.5 \times 10^{3}$ dalton) and KF-802 (exclusion limit: polystyrene, $5.0 \times 10^{3}$ dalton $)$ using THF $(1 \mathrm{~mL} /$ min) as an eluent.

\section{Reagents}

(4-Substituted phenyl)trimethoxysilanes used in this study are (4-dimethylaminophenyl)trimethoxysilane $\left[\mathrm{bp}=127-131{ }^{\circ} \mathrm{C} / 0.53\right.$ Torr $]$, (4-methoxyphenyl)trimethoxysilane $\left[\mathrm{bp}=80-81{ }^{\circ} \mathrm{C} / 0.30\right.$ Torr $]$, (4methylphenyl)trimethoxysilane $\left[\mathrm{bp}=53-54{ }^{\circ} \mathrm{C} / 0.30\right.$ Torr], phenyltrimethoxysilane $\left[\mathrm{bp}=218^{\circ} \mathrm{C}\right.$, ShinEtsu Chemical Co., Ltd., Japan without further purification], and 4-trimethoxysilylbiphenyl $\left[\mathrm{bp}=133^{\circ} \mathrm{C} /\right.$ 0.31 Torr] of purity more than $95 \%$ (GC), prepared by Grignard reaction from bromoaromatic derivatives and tetramethoxysilane followed by 1 or 2 times distillation. For example, (4-dimethylaminophenyl)trimethoxysilane was prepared by $30 \mathrm{mmol}$ of 4-bromo- $N, N$-dimethylaniline and $33 \mathrm{mmol}$ of dried magnesium turning in $100 \mathrm{~mL} 2$ mouth round bottom flask with $24 \mathrm{~mL}$ dried THF inside. After the reaction occurred, the reaction system was maintained under stirring for $2 \mathrm{~h}$. Grignard reagent obtained from the reaction was transferred to another $100 \mathrm{~mL}$ flask with dropping funnel. Grignard reagent was dropped slowly into $45 \mathrm{mmol}$ tetrachlorosilane in $24 \mathrm{~mL}$ dried THF. The reaction was stopped in ice bath. The product, (4substituted phenyl)trimethoxysilane was distilled, and the purity was checked by GC-MS. All the compounds gave reasonable NMR chemical shifts as (4-dimethylaminophenyl)trimethoxysilane: 7.53-7.50 (d, 2H), 6.75-6.72 (d, 2H), $3.60(\mathrm{~s}, 9 \mathrm{H}), 2.98$ (s, 
6H); (4-Methoxyphenyl)trimethoxysilane: 7.57-7.60 $(\mathrm{d}, 2 \mathrm{H}), 6.92-6.95(\mathrm{~d}, 2 \mathrm{H}), 3.82(\mathrm{~s}, 3 \mathrm{H}), 3.61(\mathrm{~s}$, 9H); (4-methylphenyl)trimethoxysilane: 7.56-7.53 $(\mathrm{d}, 2 \mathrm{H}), 7.23-7.21(\mathrm{~d}, 2 \mathrm{H}), 3.62(\mathrm{~s}, 9 \mathrm{H}), 2.37(\mathrm{~s}$, $3 \mathrm{H})$; 4-trimethoxysilylbiphenyl: 7.72-7.74 (d, 1H), 7.60-7.64 (m, 4H), 7.34-7.48 (m, 4H), 3.66 (s, 9H).

\section{Synthesis of Oligosilsesquioxane}

To benzene $(10 \mathrm{~mL})$ solution of a (4-substituted phenyl)trimethoxysilane $(10 \mathrm{mmol})$ in a $30 \mathrm{~mL}$ round-bottom flask, deionized water $(15 \mathrm{mmol})$ and methanolic benzyltrimethylammonium hydroxide (BTMAOH) (40\% w/w, $6 \mathrm{~mol} \%$ to the trimethoxysilane) were added. Stirring was commenced, and the reaction mixture was kept under vigorous stirring and refluxing for $4 \mathrm{~h}$. After cooled to room temperature, the precipitate formed was filtered off, and the benzene soluble oligosilsesquioxane was obtained from the filtrate by evaporating the solvent.

\section{RESULTS AND DISCUSSION}

After $4 \mathrm{~h}$ refluxing, precipitate was formed in the systems of (4-dimethylaminophenyl)-trimethoxysilane, phenyltrimethoxysilane and 4-trimethoxysilylbiphenyl. The oligosilsesquioxane was obtained from benzene solution as sticky white to pale yellow solid. Results of the synthesis are tabulated in Table I.

(4-Methoxylphenyl)trimethoxysilane gave only benzene soluble fraction after hydrolysis and condensation, and SEC of the products are typically shown in Figure 2. Products with molecular weight higher than 1500 but not more than 3000 (standard polystyrene) were obtained.

Typical change in IR spectra is shown in Figure 3 for the hydrolysis of phenyltrimethoxysilane.

A strong broad $\mathrm{OH}$ band of silanol is observed at

Table I. Fractionation of the hydrolyzate of (4-substituted phenyl)trimethoxysilane for $4 \mathrm{~h}$ under benzene refluxing condition

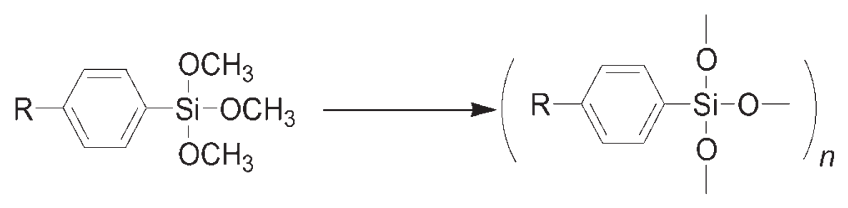

\begin{tabular}{lcc}
\hline \multirow{2}{*}{ 4-Substituent } & \multicolumn{2}{c}{ Fractionation by benzene } \\
\cline { 2 - 3 } & Soluble $(\%)$ & Insoluble $(\%)$ \\
\hline Dimethylamino & 36 & 64 \\
Methoxy & 100 & 0 \\
Methyl & 100 & 0 \\
H & 16 & 84 \\
Phenyl & 20 & 80 \\
\hline
\end{tabular}

Condition: Trimethoxysilane precursor/water/BTMAOH = $10 / 15 / 0.6 \mathrm{~mol} / \mathrm{mol} / \mathrm{mol}$. Reflux in benzene for $4 \mathrm{~h}$.

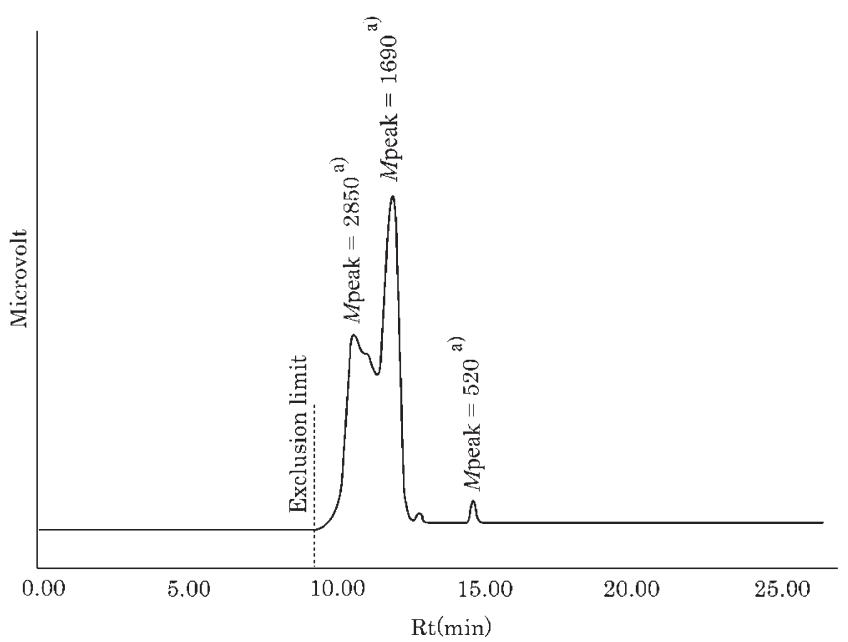

a) Molecular wight ( $M$ peak) was calculated from standard styrene.

Figure 2. SEC of benzene soluble fraction obtained from (4methoxylphenyl)trimethoxysilane.

$3300-3700 \mathrm{~cm}^{-1}$, and weak C-H stretching of starting methoxysilane precursor at 2842 and $2945 \mathrm{~cm}^{-1}$. Contrary, Si-O-C stretching at 1085 and $1192 \mathrm{~cm}^{-1}$ disappeared. This indicated that almost all of the methoxy groups were hydrolyzed to silanol. In the products, strong band of $\mathrm{Si}-\mathrm{O}-\mathrm{Si}$ asymmetric stretching was observed at $1000-1200 \mathrm{~cm}^{-1}$ (Figure 3). Benzene insoluble fraction gave sharper and narrower $\mathrm{Si}-$ $\mathrm{O}-\mathrm{Si}$ asymmetric stretching than that of soluble product.

In ${ }^{1} \mathrm{H}$ NMR, broad peaks were observed for incompletely hydrolyzed groups of phenyltrimethoxysilane at $\delta=2.8-3.5 \mathrm{ppm}$ (Figure 4 ), even after $4 \mathrm{~h}$ under the experiment condition. The aromatic peak also appeared as the broad peaks $(\delta=6.5-8.0 \mathrm{ppm})$ in benzene soluble product. Further treatment under the same condition (benzene $=10 \mathrm{~mL}$, deionized water $=15 \mathrm{mmol}$, methanolic BTMAOH: $40 \% \mathrm{w} / \mathrm{w}=$ $5 \mathrm{~mL}$ ) completely cleaved the silicon methoxy bond as evidenced by the disappearance of methoxy groups in IR spectra.

In ${ }^{29} \mathrm{Si}$ solid state NMR, typically shown for the product from phenyltrimethoxysilane, in Figure 5, benzene soluble oligosilsesquioxanes obtained from all (4-substituted phenyl)trimethoxysilane showed 2 principal peaks in the range of $\delta=-69$ to -72 , and -78 to $-81 \mathrm{ppm}$ (Table II), assignable to $\mathrm{T}^{2}$ and $\mathrm{T}^{3}$ structure, ${ }^{16}$ while no $\mathrm{T}^{1}$ signal was observed (see Figure 6). Contrary, insoluble fraction showed only $\mathrm{T}^{3}$.

It might be suggested that the benzene soluble fraction had many complex structures ${ }^{17}$ with hydroxyl groups. Contrary, insoluble fraction might be composed of highly symmetrical structures. ${ }^{18}$ This discussion will be described in the following report, since MS has not been obtained for these samples. 


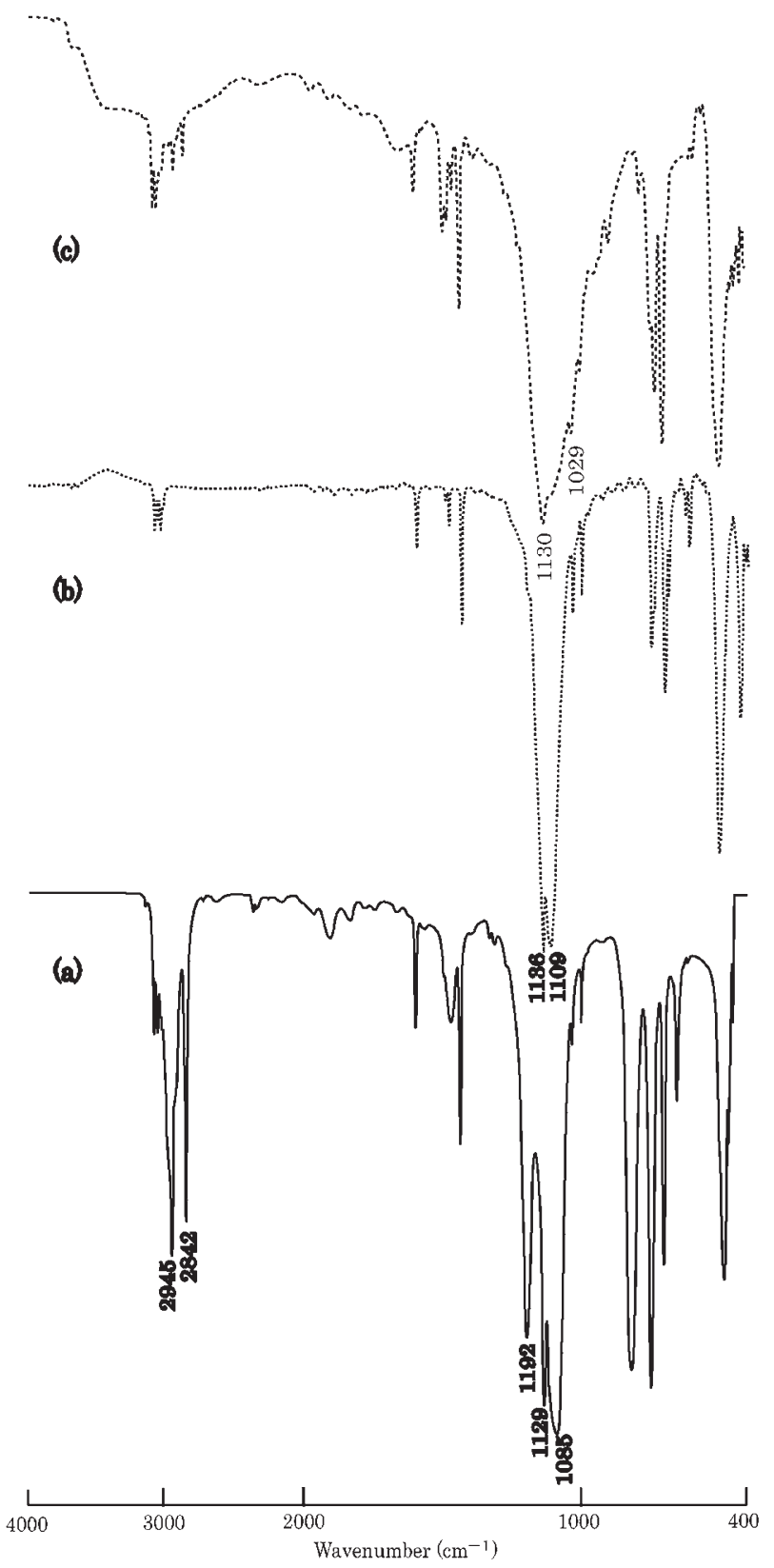

Figure 3. IR spectra in the hydrolysis of phenyltrimethoxysilane: (a) starting phenyltrimethoxysilane, (b) benzene insoluble fraction, (c) benzene soluble fraction.

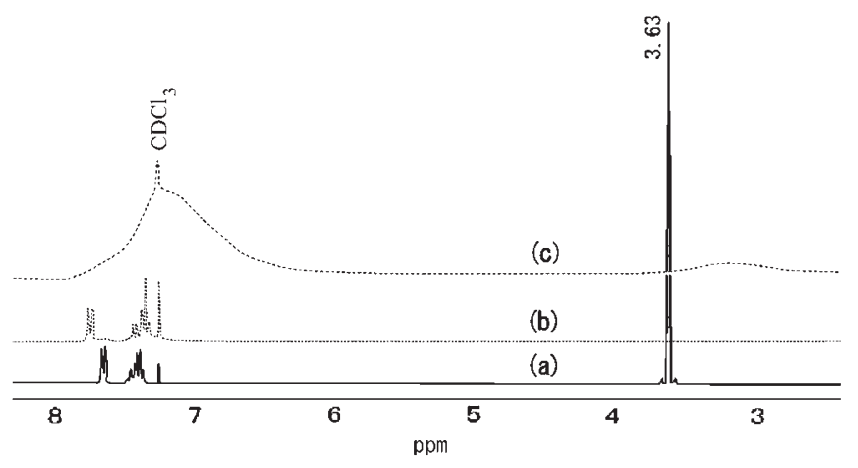

Figure 4. ${ }^{1}$ H NMR spectra of: (a) phenyltrimethoxysilane, (b) benzene insoluble fraction, (c) benzene soluble fraction.

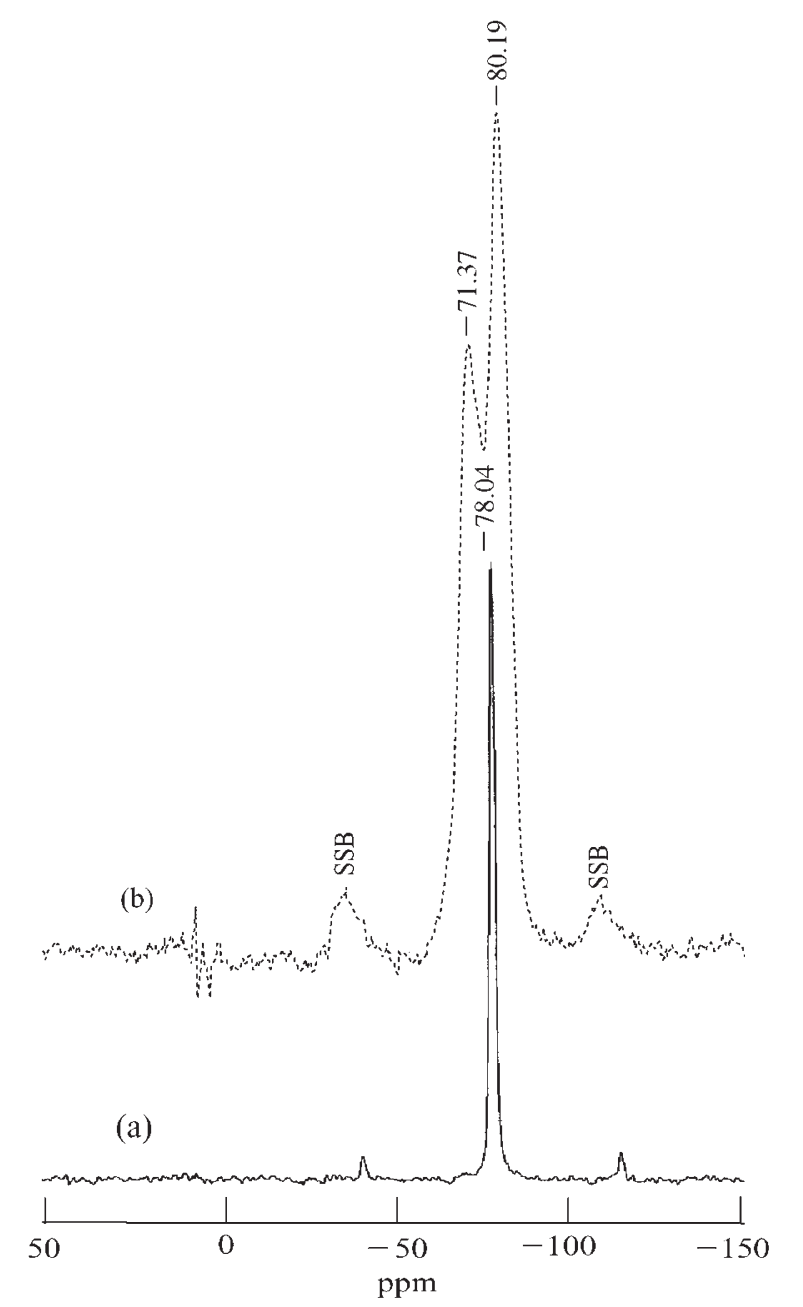

Figure 5. $\mathrm{CP} / \mathrm{MAS}$ solid state ${ }^{29} \mathrm{Si} \mathrm{NMR}$ of: (a) benzene insoluble fraction, (b) benzene soluble fraction.

Table II. Solid state ${ }^{29}$ Si NMR of benzene soluble fraction from (4-substituted phenyl)trimethoxysilanes

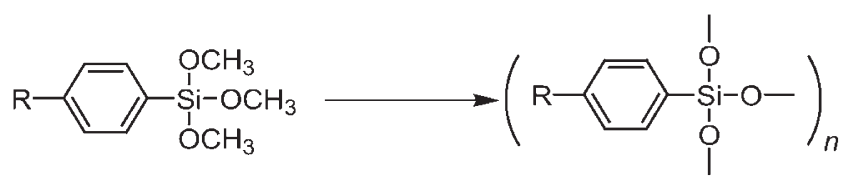

\begin{tabular}{lc}
\hline 4-Substituent & ppm \\
\hline Dimethylamino & $-69.59,-77.97$ \\
Methoxy & $-70.55,-79.35$ \\
Methyl & $-71.33,-79.62$ \\
H & $-71.37,-80.20$ \\
Phenyl & -73.25 (overlap), -79.47 \\
\hline
\end{tabular}

\begin{tabular}{|c|c|c|c|c|}
\hline Chemical structur & 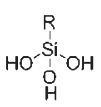 & 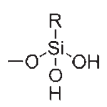 & 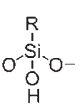 & 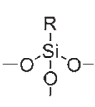 \\
\hline Abbreviation & $T^{0}$ & $T^{1}$ & $T^{2}$ & $T^{3}$ \\
\hline
\end{tabular}

Figure 6. Abbreviation of siloxane structure. 


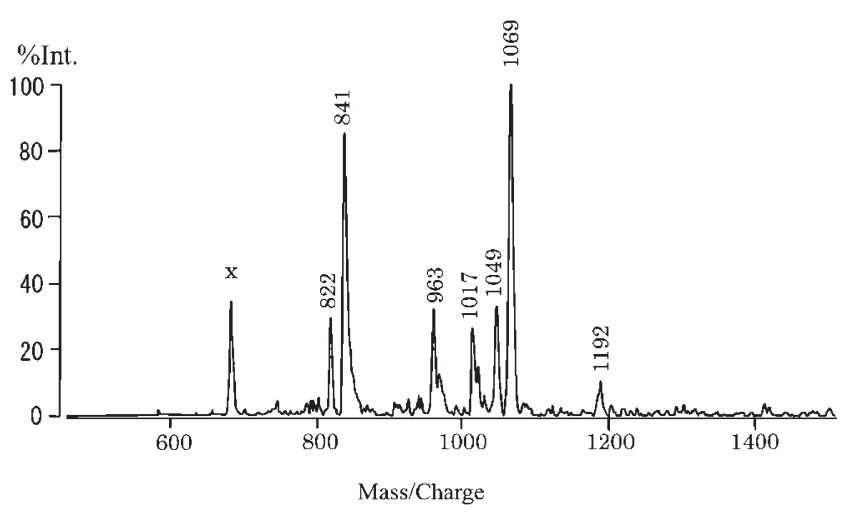

Figure 7. MALDI-TOF MS spectrum of the benzene soluble fraction from phenyltrimethoxysilane precursor.

Typical MALDI-TOF MS of soluble fraction is shown in Figure 7.

MALDI-TOF MS shows multiple peaks in all samples. In the discussion of the oligosilsesquioxane structure, the expression of the structure was simplified by representing with dot and line symbols. Dot indicates the silicon atom, and line is siloxane bond as shown in Figure 8. The dot connecting to only 1 line indicates $\mathrm{T}^{1}$ structure. Dot connecting to 2 and 3 lines indicates $\mathrm{T}^{2}$ and $\mathrm{T}^{3}$ structure, respectively. Assignment to each peak was made by considering the degree of condensation. Degree of condensation $(f)$ was defined as the extent of intramolecular condensation between 2 silanol groups as typically shown, assuming the formation of 8-membered ring, in the cases of 7 and 8 silicon atom containing oligosilsesquioxanes (Figure 9).

In general, $f$ can be defined by the number of loops in the structure.

$$
f=t / t_{\mathrm{m}}
$$

where, $t$ is the number of closed loop in the oligosilsesquioxane, $t_{\mathrm{m}}$ is the number of maximum closed loops possible in the oligosilsesquioxane with $n$ silicon atoms and $n$ is the number of silicon atom in the oligosilsesquioxane.

$$
t_{\mathrm{m}}= \begin{cases}n / 2+1, & \text { if } n=\text { even number } \\ (n-1) / 2+1, & \text { if } n=\text { odd number }\end{cases}
$$

According to Figure 9, for example of 8 silicon atom containing system, 10 silanols (when no cyclic structure existing) can condense to form maximum 5 loops (when perfectly cyclized). When the fifth loop is formed, the sixth loop is simultaneously formed. Degree of condensation by the formation of one loop $(f)$ is 0.20 (calculated following $\mathrm{Eq} 1$, where $t=1$, and $t_{\mathrm{m}}=5$ ). In case of 7 silicon atom-containing system, 8 out of 9 silanols can condense to form maximum 4 loops structure. Therefore, degree of condensation by the formation of one loop $(f)$ is 0.25 (where $t=1$, and $t_{\mathrm{m}}=4$ ).

Since one water molecule is lost on each condensation, the molecular weight decreases by 18 on each cyclization. The molecular weight of oligosilsesquioxane $(M)$ can be calculated, according to Eq 2, by adding 18 (terminal $\mathrm{OH}$ and $\mathrm{H}$ ).

$$
M=n \times M_{\text {unit }}-18 \mathrm{t}+18
$$

where, $M$ is the mass of the oligosilsesquioxane with $\mathrm{n}$ silicon atoms, $M_{\text {unit }}$ is the mass of the unit fraction $\left[\mathrm{O}_{0.5}(\mathrm{RSiOH}) \mathrm{O}_{0.5}\right]$.

The signals of MS spectra can be classified into several groups based on the number of silicon atoms (n). The number of non-condensed $\mathrm{OH}$ in each compound in the group depends on the degree of condensation, namely the number of the loops $(t)$. The mother frameworks of oligosilsesquioxanes consisting of 6 , 7,8 , and $n$ silicon atoms were abbreviated as $S_{6}, S_{7}$, $\mathrm{S}_{8}$, and $\mathrm{S}_{n}$. Hereafter, $\mathrm{S}_{n}(\mathrm{OH})_{x}$ is defined as oligosilsesquioxane with $n$ silicon atoms and $x$ non-condensed OH groups. $\mathrm{S}_{n}(\mathrm{OH})_{n+2}$ is converted to $\mathrm{S}_{n}(\mathrm{OH})_{n}$ when one condensation occurs to form one loop (Figure 10).

Each peak in MS could be assigned, and the degree of condensation $(f)$ was calculated as shown in Table III.

In benzene soluble fraction, oligosilsesquioxanes containing 6 to 9 silicon atoms, with loops but incompletely cyclized to cage structure, were observed as the main products. With 4-dimethylamino substituent, $\mathrm{S}_{8}$ and $\mathrm{S}_{9}$ fractions were formed the most with small amounts of $\mathrm{S}_{6}$ fraction, and the amount of $\mathrm{S}_{9}$ was the highest among the compounds studied. Contrary, $\mathrm{S}_{9}$ was the least for [methoxy (10\%)-, non (3\%)-

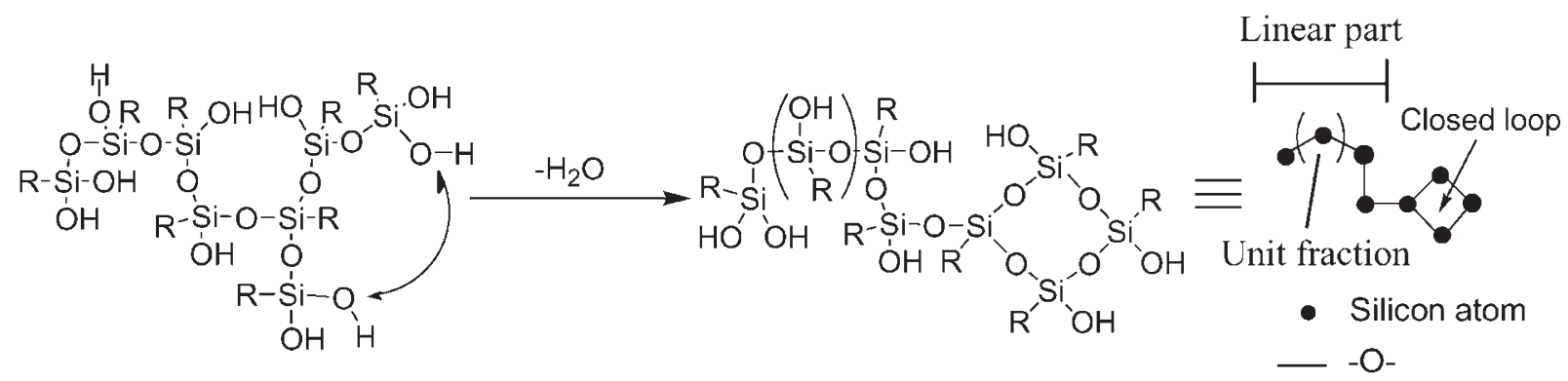

Figure 8. A typical oligosilsesquioxane structure represented by dot and line. 


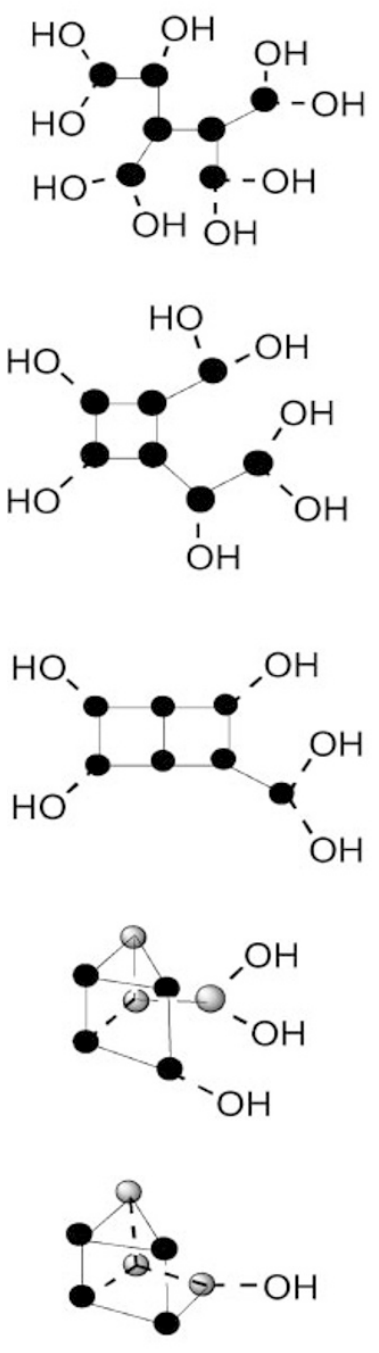

$$
f=0.00
$$<smiles>OC(O)[C@@H](O)[C@@H](O)[C@@H](O)[C@@H](O)[C@@H](O)C(O)O</smiles>

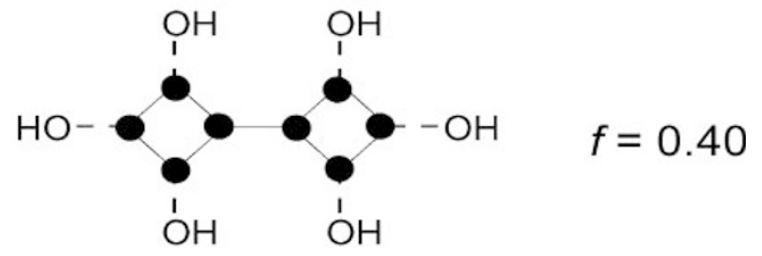<smiles>OC1[C@@H]2[C@@H]([C@H]1O)[C@@H](O)[C@@H]2O</smiles>

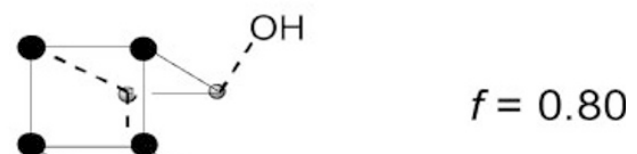

$f=1.00$

- R-Si

- R-Si (in different plane) -O-

Figure 9. Illustration of the degree of condensation $(f)$.
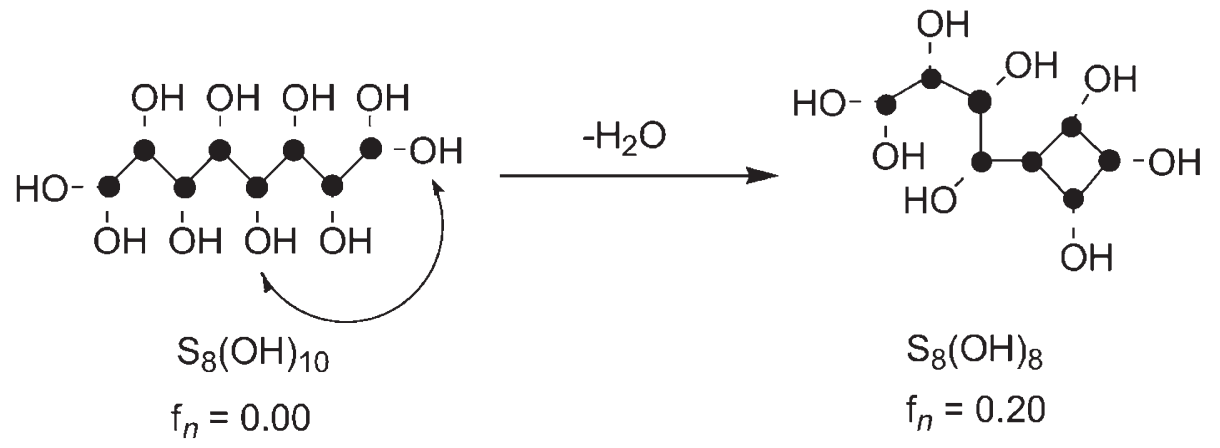

Figure 10. Conversion of $S_{8}(\mathrm{OH})_{10}$ to $S_{8}(\mathrm{OH})_{8}$ by one loop formation. 
Table III. MS peak assignment and $(f)$ value for the products from (4-substituted phenyl)trimethoxysilanes

\begin{tabular}{|c|c|c|c|c|c|c|c|c|}
\hline $\mathrm{R}$ & Assignment & $M_{\text {calc. }}$ & $\begin{array}{c}M_{\text {meas. }} \\
{[\mathrm{M}+\mathrm{H}]^{+}}\end{array}$ & $\Sigma f_{\mathrm{Hi}}$ & $f_{\mathrm{Hi}}$ & $f$ & $f \times f_{\mathrm{Hi}}$ & $\frac{f \times f_{\mathrm{Hi}}}{\sum\left(f \times f_{\mathrm{Hi}}\right)}$ \\
\hline \multirow{9}{*}{$\mathrm{Me}_{2} \mathrm{~N}-$} & $\mathrm{S}_{6}(\mathrm{OH})_{8}$ & 1105.6 & 1106 & 0.03 & 0.03 & 0.00 & 0.000 & 0.000 \\
\hline & $\mathrm{S}_{7}(\mathrm{OH})_{5}$ & 1250.8 & 1249 & \multirow{2}{*}{0.16} & 0.08 & 0.50 & 0.040 & 0.056 \\
\hline & $\mathrm{S}_{7}(\mathrm{OH})_{4}\left(\mathrm{OCH}_{3}\right)$ & 1264.9 & 1264 & & 0.08 & 0.50 & 0.040 & 0.056 \\
\hline & $\mathrm{S}_{8}(\mathrm{OH})_{2}$ & 1396.1 & 1393 & \multirow{3}{*}{0.45} & 0.12 & 0.80 & 0.096 & 0.135 \\
\hline & $\mathrm{S}_{8}(\mathrm{OH})\left(\mathrm{OCH}_{3}\right)$ & 1410.1 & 1409 & & 0.26 & 0.80 & 0.208 & 0.292 \\
\hline & $\mathrm{S}_{8}(\mathrm{OH})_{8}$ & 1450.1 & 1449 & & 0.07 & 0.20 & 0.014 & 0.020 \\
\hline & $\mathrm{S}_{9}(\mathrm{OH})$ & 1559.3 & 1562 & \multirow{2}{*}{0.36} & 0.13 & 1.00 & 0.130 & 0.183 \\
\hline & $\mathrm{S}_{9}(\mathrm{OH})_{3}$ & 1577.3 & 1577 & & 0.23 & 0.80 & 0.184 & 0.258 \\
\hline & & & Total & 1.00 & 1.00 & - & 0.712 & 1.000 \\
\hline \multirow{8}{*}{$\mathrm{MeO}-$} & $\mathrm{S}_{6}(\mathrm{OH})_{8}$ & 1027.3 & 1025 & 0.43 & 0.43 & 0.00 & 0.000 & 0.000 \\
\hline & $\mathrm{S}_{7}(\mathrm{OH})_{5}$ & 1159.5 & 1159 & \multirow{2}{*}{0.23} & 0.10 & 0.50 & 0.050 & 0.151 \\
\hline & $\mathrm{S}_{7}(\mathrm{OH})_{7}$ & 1177.6 & 1175 & & 0.13 & 0.25 & 0.032 & 0.096 \\
\hline & $\mathrm{S}_{8}(\mathrm{OH})_{2}$ & 1291.7 & 1290 & \multirow{2}{*}{0.23} & 0.10 & 0.80 & 0.080 & 0.241 \\
\hline & $\mathrm{S}_{8}(\mathrm{OH})_{4}$ & 1309.7 & 1307 & & 0.13 & 0.60 & 0.078 & 0.235 \\
\hline & $\mathrm{S}_{9}(\mathrm{OH})$ & 1441.9 & 1442 & \multirow{2}{*}{0.10} & 0.06 & 1.00 & 0.060 & 0.181 \\
\hline & $\mathrm{S}_{9}(\mathrm{OH})_{3}$ & 1460.0 & 1456 & & 0.04 & 0.80 & 0.032 & 0.096 \\
\hline & & & Total & 0.99 & 0.99 & - & 0.332 & 1.000 \\
\hline \multirow{9}{*}{$\mathrm{Me}-$} & $\mathrm{S}_{6}(\mathrm{OH})_{8}$ & 931.3 & 928 & 0.19 & 0.19 & 0.00 & 0.000 & 0.000 \\
\hline & $\mathrm{S}_{7}(\mathrm{OH})_{5}$ & 1047.6 & 1047 & \multirow{2}{*}{0.31} & 0.13 & 0.50 & 0.065 & 0.158 \\
\hline & $\mathrm{S}_{7}(\mathrm{OH})_{7}$ & 1065.6 & 1064 & & 0.18 & 0.25 & 0.045 & 0.109 \\
\hline & $\mathrm{S}_{8}(\mathrm{OH})_{2}$ & 1163.7 & 1165 & \multirow{2}{*}{0.28} & 0.10 & 0.80 & 0.080 & 0.194 \\
\hline & $\mathrm{S}_{8}(\mathrm{OH})_{4}$ & 1181.8 & 1182 & & 0.18 & 0.60 & 0.108 & 0.262 \\
\hline & $\mathrm{S}_{9}(\mathrm{OH})$ & 1298.0 & 1299 & \multirow{3}{*}{0.22} & 0.05 & 1.00 & 0.050 & 0.121 \\
\hline & $\mathrm{S}_{9}(\mathrm{OH})_{3}$ & 1316.0 & 1315 & & 0.08 & 0.80 & 0.064 & 0.155 \\
\hline & $\mathrm{S}_{9}(\mathrm{OH})_{9}\left(\mathrm{OCH}_{3}\right)_{2}$ & 1416.1 & 1416 & & 0.09 & 0.00 & 0.000 & 0.000 \\
\hline & & & Total & 1.00 & 1.00 & - & 0.412 & 1.000 \\
\hline \multirow{8}{*}{$\mathrm{H}-$} & $\mathrm{S}_{6}(\mathrm{OH})_{6}$ & 829.2 & 822 & \multirow{2}{*}{0.36} & 0.09 & 0.25 & 0.022 & 0.061 \\
\hline & $\mathrm{S}_{6}(\mathrm{OH})_{8}$ & 847.2 & 841 & & 0.27 & 0.00 & 0.000 & 0.000 \\
\hline & $\mathrm{S}_{7}(\mathrm{OH})_{7}$ & 967.4 & 963 & \multirow{2}{*}{0.18} & 0.10 & 0.25 & 0.025 & 0.069 \\
\hline & $\mathrm{S}_{7}(\mathrm{OH})_{3}\left(\mathrm{OCH}_{3}\right)_{4}$ & 1023.5 & 1017 & & 0.08 & 0.25 & 0.020 & 0.055 \\
\hline & $\mathrm{S}_{8}(\mathrm{OH})_{2}$ & 1051.5 & 1049 & \multirow{2}{*}{0.42} & 0.10 & 0.80 & 0.192 & 0.529 \\
\hline & $\mathrm{S}_{8}(\mathrm{OH})_{4}$ & 1069.5 & 1069 & & 0.32 & 0.60 & 0.080 & 0.220 \\
\hline & $\mathrm{S}_{9}(\mathrm{OH})_{3}$ & 1189.7 & 1192 & 0.03 & 0.03 & 0.80 & 0.024 & 0.066 \\
\hline & & & Total & 0.99 & 0.99 & - & 0.363 & 1.000 \\
\hline \multirow{7}{*}{$\mathrm{Ph}-$} & $\mathrm{S}_{6}(\mathrm{OH})_{7}\left(\mathrm{OCH}_{3}\right)$ & 1317.8 & 1314 & 0.29 & 0.29 & 0.00 & 0.000 & 0.000 \\
\hline & $\mathrm{S}_{7}(\mathrm{OH})_{5}$ & 1482.0 & 1486 & \multirow{2}{*}{0.20} & 0.03 & 0.50 & 0.015 & 0.036 \\
\hline & $\mathrm{S}_{7}(\mathrm{OH})_{7}$ & 1500.1 & 1501 & & 0.17 & 0.25 & 0.042 & 0.102 \\
\hline & $\mathrm{S}_{8}(\mathrm{OH})_{2}$ & 1660.3 & 1657 & \multirow{2}{*}{0.36} & 0.04 & 0.80 & 0.032 & 0.078 \\
\hline & $\mathrm{S}_{8}(\mathrm{OH})_{4}$ & 1678.3 & 1674 & & 0.32 & 0.60 & 0.192 & 0.467 \\
\hline & $\mathrm{S}_{9}(\mathrm{OH})$ & 1856.4 & 1859 & 0.13 & 0.13 & 1.00 & 0.130 & 0.036 \\
\hline & & & Total & 0.98 & 0.98 & - & 0.411 & 0.999 \\
\hline
\end{tabular}

$\mathrm{S}_{n}$ : the oligosilsesquioxane with $n$ silicon atoms,

$f_{\mathrm{Hi}}$ : a mass peak's height of each fraction in the same $n$ silicon atom-containing oligosilsesquioxane,

$f \times f_{\mathrm{Hi}}$ : mole fraction of components with loop(s) in the same $n$ silicon atom-containing oligosilsesquioxane.

and phenyl (13\%)-substituted]phenyltrimethoxysilane. This seemed to indicate that the intermolecular condensation of silanol groups in the hydrolyzate of (4-dimethylaminophenyl)trimethoxysilane is faster than those with other substituents. Fractions containing 7 and 8 silicon atoms are the major fractions of the products irrespective of the substituent. Definite trend in the relative rate of the intermolecular conden- 
sation could not be observed for the different substituents. Solubility of the compounds and steric effect might also have big influences on the reaction rate. Eight silicon atom-containing systems had degree of condensation $(f)=0.6$ and 0.8 . Nine silicon-containing systems had $f=0.80$ and 1.00 . The degree of condensation (extent of loop formation) was the highest for 9 silicon-containing systems. It is worth to note that there were not much oligomer fractions higher than $S_{10}$ in hydrolysis with any kinds of 4-substituent of oligosilsesquioxanes. It was believed that the bulky aryl-substituent compared with alkyl substituent had the tendency to give low molecular weight products as the soluble products composed of mainly $\mathrm{S}_{6}-\mathrm{S}_{9}$ fractions in weak BTMAOH hydrolysis system.

$\mathrm{S}_{6}$ system had little tendency to form loops for any (4-substituted phenyl)trimethoxysilane (found 9\% in only phenyl substituted system). The high mobility of the molecule might make the molecule difficult to bring two silanols function together. Only one loop in low silicon containing system $(n<7)$ might be unable to stabilize the system. The tendency became higher with the increasing in silicon number of the oligosilsesquioxane, namely $\mathrm{S}_{7}$ (maximum $f=0.50$ ), $\mathrm{S}_{8}$ (maximum $f=0.80$ ), and $\mathrm{S}_{9}$ (maximum $f=1.00$ ) formed loops in much higher concentration. Such loop structure might become stable when silicon number increased. This tendency was not much affected by the difference of 4-substituent of phenyl group.

If the major loop is assumed as 8-membered ring, the existence of $\mathrm{S}_{7}(\mathrm{OH})_{7}, \mathrm{~S}_{7}(\mathrm{OH})_{5}$ and almost non-existence of $\mathrm{S}_{7}(\mathrm{OH})_{3}$ and $\mathrm{S}_{7}(\mathrm{OH})$ might indicate easy formation of the first 8 -membered ring $(n=4)$ as the loop, but successive loop formations were difficult. The maximum $f$ value of 0.5 for $\mathrm{S}_{7}$ fraction might indicate the difficulty of the formation of 6membered ring as the third loop. In $\mathrm{S}_{8}$ system, $\mathrm{S}_{8}(\mathrm{OH})_{4}$ and $\mathrm{S}_{8}(\mathrm{OH})_{2}$ were principal products. Formation of fused two 8-membered loop with a sheet structure was probable. To make one more loop, the molecule should be bent. Apparently this process is not difficult because similar amounts of $\mathrm{S}_{8}(\mathrm{OH})_{2}$ with $\mathrm{S}_{8}(\mathrm{OH})_{4}$ were formed. The maximum value of 0.8 for $\mathrm{S}_{8}$ fraction might indicate that the loop formation to cage structure was difficult because the remaining two silanols were not necessary located close to each other. Although the amounts of $S_{9}$ were smaller than $\mathrm{S}_{6}-\mathrm{S}_{8}$, the tendency of forming the complete loop structure was the highest. Detailed structural analysis will be reported elsewhere.

In our experiment, (4-substituted phenyl)trimethoxysilane was used as the precursor for hydrolysis and condensation instead of phenyltrichlorosilane used by Brown et al. ${ }^{13}$ in the presence of BTMAOH to avoid the effects of acid liberated which tended to give high molecular weight products, probably because of increasing the rate of condensation reaction of silanol groups. Different from trichlorosilane as the precursor, trimethoxysilane hydrolysis reaction proceeded under easily controllable mild conditions. Under controlled weakly basic condition, it would be reasonable to consider that oligosilsesquioxane was produced by adding phenylsilano one by one as proposed by Kim et al, ${ }^{19}$ without breaking of already formed siloxane bonds.

When hydrolysis reaction of methoxy groups attached to silicon atoms occurs, formation and condensation of silanol will proceed. The structure and reactivity of the silanol groups of the initially formed oligosilsesquioxane will basically determine the structure of the products, and eventually the loop structure produced by condensation of silanol groups. The possible initially formed linear or low branched-structures of $S_{6}, S_{7}$ and $S_{8}$ systems, for examples, were shown in Figure 11.

If hydrolysis of three methoxy groups is similarly fast, condensation of silanol functions shall give random branching in the product to form highly branched structure. $\mathrm{Ng}$ et al. pointed out the failure of random branching theory, which is based on the equal reactivity of ethoxy groups, in tetraethoxysilane hydrolysis, gave cyclic structure in the early stage of the reaction. ${ }^{20} \mathrm{We}$ also elucidated the faster hydrolysis of the first and second silane groups by water than the third silane function in the presence of palladium catalyst, ${ }^{21}$ and that the formed silanol groups condensed at the similar or slower rate with hydrolysis. ${ }^{22,23} \mathrm{We}$ assumed the hydrolysis of one methoxy group is slower than the other two methoxy groups, and than condensation between two silanol groups, linear or low branch structure will be basically formed as the initial products. The aromatic moiety might have functioned to differentiate the reactivity of three methoxy groups (two methoxy groups of higher and one with lower reactivity) in the hydrolysis process and possibly to give low branch structure soluble in benzene among many possible condensed oligomeric intermediate. Rather broad chemical shifts in ${ }^{1} \mathrm{H}$ NMR seemed to reflect the difference in the degree of polymerization, which resulted in the presence of a variety of the chemical environment in the products.

When $\mathrm{T}^{1}$ and $\mathrm{T}^{2}$ structure were produced in the initial step in linear or low branch structure, they could further condense to form loop structure. The loop structure of $6(n=3)-, 8(n=4)-, 10(n=5)-$, and $12(n=6)$-membered rings, as shown in Figure 12. Substituents would affect the rate of hydrolysis and condensation to result in the different structure of low branched compounds in the initial step. The longer chain structure seemed to have higher possibility to 


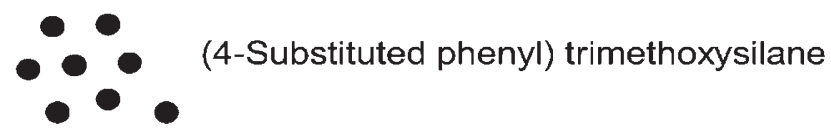

Hydrolysis, condensation

$s_{6}$

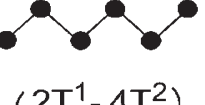

$\left(2 T^{1}-4 T^{2}\right)$

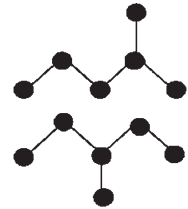

$\left(3 T^{1}-2 T^{2}-T^{3}\right)$

$\mathrm{S}_{7}$
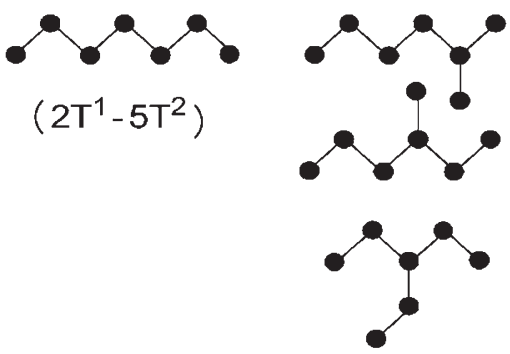

$\left(3 T^{1}-3 T^{2}-T^{3}\right)$

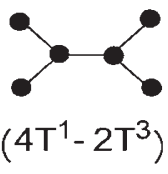

$\left(4 T^{1}-2 T^{3}\right)$

$\mathrm{S}_{8}$

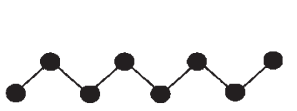

$\left(2 T^{1}-6 T^{2}\right)$
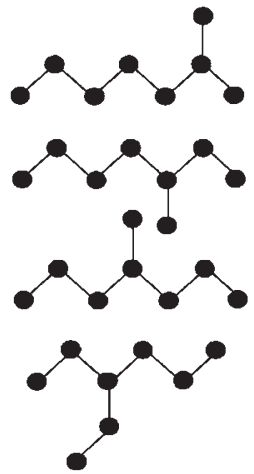

$\left(3 \mathrm{~T}^{1}-4 \mathrm{~T}^{2}-\mathrm{T}^{3}\right)$
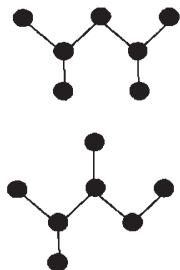

$\left(4 T^{1}-T^{2}-2 T^{3}\right)$
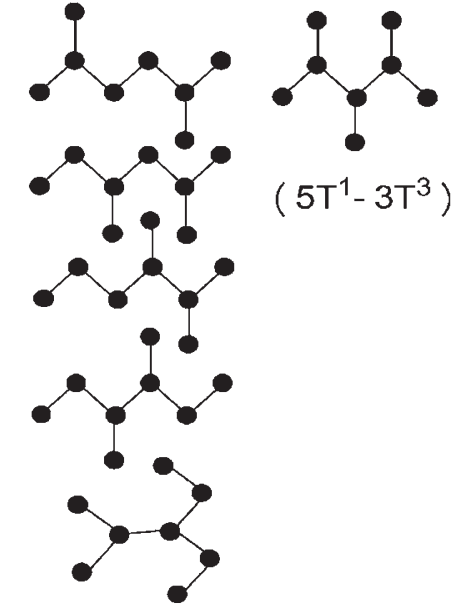

$\left(4 T^{1}-2 T^{2}-2 T^{3}\right)$

Figure 11. Possible isomeric structures of oligosilsesquioxane $S_{6}, S_{7}$ and $S_{8}$. Possible combination of siloxane is indicated in parenthesis.

form loop structure by intramolecular condensation. 8-Membered ring might be the most stable loop formed via intramolecular condensation, and eventually contribute to the formation of cage structure. This trend was more notable in aromatic-substituted system than aliphatic system. ${ }^{4,24}$

\section{CONCLUSIONS}

Hydrolysis condensation of (4-substituted phenyl)- trimethoxysilane in BTMAOH/benzene, was studied by IR, solid-state ${ }^{29} \mathrm{Si}$ NMR, and by MALDI-TOF MS. The hydrolysis seemed to firstly form linear or low branch structure containing 6-9 silicon atoms by intermolecular condensation. $\mathrm{S}_{6}-\mathrm{S}_{8}$ fraction was formed the most. With more silicon atoms contained in the initial products, tendency of loop formation increased irrespectively of the 4-substituent. In benzene soluble portion of hydrolyzed products, maximum degree of condensation $(f)$ was 0.8 for $\mathrm{S}_{8}$, and fully con- 


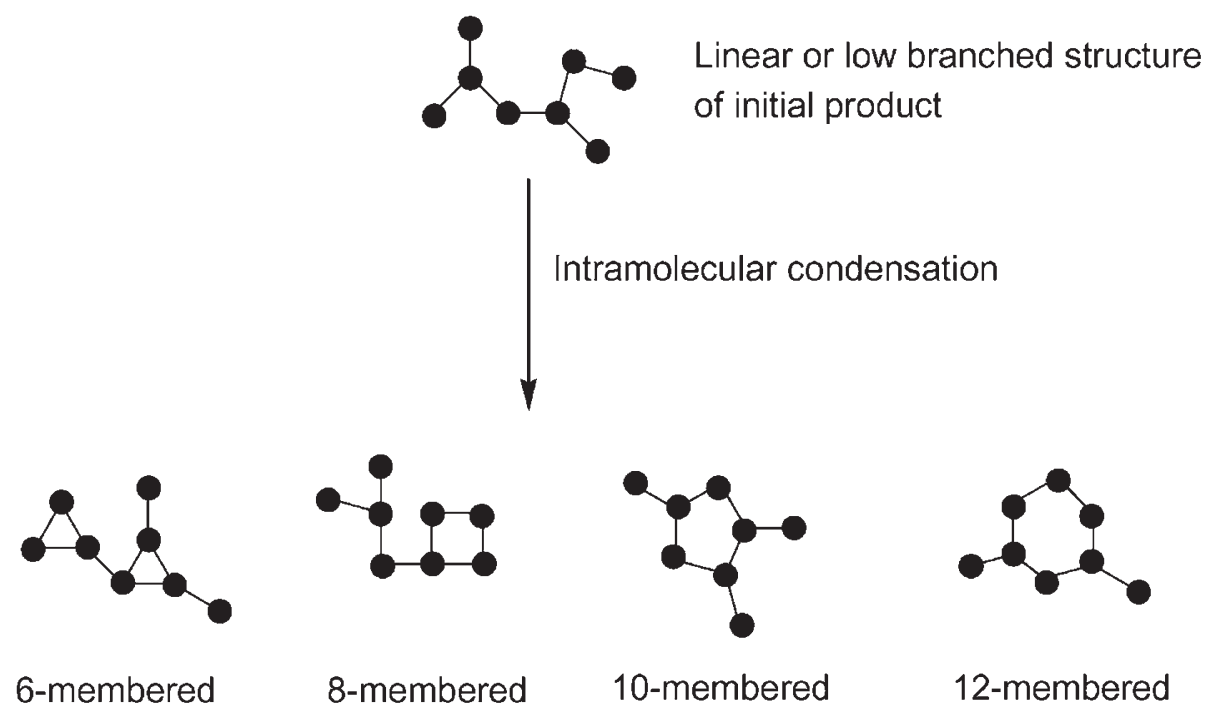

Figure 12. Possible structures from low branched $S_{8}$.

densed structure was not found. The maximum $f=1.00$, and completely closed loop was found in $\mathrm{S}_{9}$ with one $\mathrm{OH}$ group remaining.

Acknowledgment. This work was also carried out partly in Nanotechnology Glass Project as part of Nanotechnology Material Program supported by New Energy and Industrial Technology Development Organization (NEDO).

\section{REFERENCES}

1. R. H. Baney, M. Itoh, A. Sakakibara, and T. Suzuki, Chem. Rev., 95, 1409 (1995).

2. D. A. Loy and K. J. Shea, Chem. Rev., 95, 1431 (1995).

3. D. A. Loy, B. M. Baugher, C. R. Baugher, D. A. Schneider, and K. Rahimian, Chem. Mater., 12, 3624 (2000).

4. L. Matejka, O. Dukh, D. Hlavata, B. Meissner, and J. Brus, Macromolecules, 4, 6904 (2001).

5. J. F. Brown, Jr., J. Am. Chem. Soc., 87, 4317 (1965).

6. P. A. Agarkar, V. W. Day, and W. G. Klemperer, J. Am. Chem. Soc., 109, 5554 (1987).

7. P. G. Harrison, J. Organomet. Chem., 542, 141 (1997).

8. P. G. Harrison and R. Kannengieser, J. Chem. Soc. Chem. Commun., 415 (1996).

9. a) F. J. Feher, D. A. Newman, and J. F. Walzer, J. Am. Chem. Soc., 111, 1741 (1989).

b) F. J. Feher, K. J. Weller, and J. J. Schwab, Organometallics, 14, 2009 (1995).

c) J. D. Lichtenhan, Y. A. Otonari, and M. J. Carr, Macromolecules, 28, 8435 (1995).
10. F. J. Feher and T. A. Budzichowsky, Polyhedral, 14, 3239 (1995).

11. J. F. Brown, Jr., L. H. Vogt, Jr., A. Katchman, J. W. Eustance, and K. M. Kiser, J. Am. Chem. Soc., 82, 6194 (1960).

12. A. J. Barry, W. H. Daudt, J. J. Domicone, and J. W. Gilkey, J. Am. Chem. Soc., 77, 4248 (1955).

13. J. F. Brown, Jr., L. H. Vogt, Jr., and P. I. Prescott, J. Am. Chem. Soc., 86, 1120 (1964).

14. W. E. Wallace, C. M. Guttman, and J. M. Antonucci, Polymer, 41, 2219 (2000).

15. R. O. R. Costa, W. L. Vasconcelos, R. Tamaki, and R. M. Laine, Macromolecules, 34, 5398 (2001).

16. K. Itoh, "Silicone Handbook," Nikkan Kogyo Shimbunsha, Tokyo, 1990.

17. M. Seino, I. Imae, and Y. Kawakami, Polym. J., 35, 197 (2003).

18. D. P. Fasce, R. J. J. Williams, R. E. Balsells, Y. Ishikawa, and H. Nonami, Macromolecules, 34, 3534 (2001).

19. H. J. Kim, J. K. Lee, S. J. Park, H. W. Ro, D. Y. Yoo, and D. Y. Yoon, Anal. Chem., 72, 5673 (2000).

20. L. V. Ng, P. Thompson, J. Sanchez, W. M. Christopher, and A. V. McCormick, Macromolecules, 28, 6471 (1995).

21. M. Seino, M. Oishi, I. Imae, and Y. Kawakami, Polym. J., 34, 43 (2002).

22. M. Seino, I. Imae, and Y. Kawakami, Polym. J., 35, 197 (2003).

23. T. Kudo and M. S. Gordon, J. Phys. Chem. A, 106, 11347 (2002).

24. P. Eisenberg, R. A. Balsells, Y. Ishikiawa, J. C. Lucas, H. Nonami, and J. J. Williams, Macromolecules, 35, 1160 (2002). 